\title{
Adherence to national guidelines for children with asthma at primary health centres in Sweden: potential for improvement
}

\author{
*Marina Jonsson ${ }^{\mathrm{a}, \mathrm{b}, \mathrm{c}}$, Ann-Charlotte Egmar ${ }^{\mathrm{d}}$, Anna Kiessling ${ }^{\mathrm{e}}$, Maria Ingemansson ${ }^{\mathrm{a}, \mathrm{b}, \mathrm{c}, \mathrm{f}}$, \\ Gunilla Hedlin ${ }^{\mathrm{b}, \mathrm{c}, \mathrm{f}}$, Ingvar Krakau ${ }^{\mathrm{g}, \mathrm{h}}$, Eva Hallneri, Inger Kulli,j,k
}

a Pediatric Outpatient Clinic, Astrid Lindgrens Children's Hospital, Stockholm, Sweden

${ }^{b}$ Department of Women's and Children's Health, Karolinska Institutet, Stockholm, Sweden

Centre for Allergy Research, Karolinska Institutet, Stockholm, Sweden

'The Red Cross University College, Stockholm, Sweden

e Department of Clinical Sciences, Danderyd Hospital, Karolinska Institutet, Stockholm, Sweden

' Astrid Lindgrens Children's Hospital, Karolinska University Hospital, Stockholm, Sweden

${ }^{g}$ Center for Family and Community Medicine, Stockholm, Sweden

${ }^{\text {h }}$ Department of Solna, Karolinska Institutet, Stockholm, Sweden

Institute of Environmental Medicine, Karolinska Institutet, Stockholm, Sweden

Sachs' Children's Hospital Södersjukhuset, Stockholm, Sweden

${ }^{k}$ Department of Clinical Science and Education, Södersjukhuset, Karolinska Institutet, Stockholm, Sweden

Received 9th November 2011; resubmitted 24th January 2012; revised 9th March 2012; accepted 25th March 2012; online 29th June 2012

\begin{abstract}
Background: Although asthma is the most common chronic paediatric disease in Western Europe, the extent of adherence to guidelines for primary care management of paediatric asthma remains unclear.

Aims: To evaluate adherence to national guidelines for primary care management of children with asthma.

Methods: This survey involved 18 primary healthcare centres in Stockholm, Sweden. The medical records of 647 children aged 6 months to 16 years with a diagnosis of asthma, obstructive bronchitis, or cough were selected and scrutinised. 223 children with obstructive bronchitis or cough not fulfilling the evidence-based criteria for asthma were excluded, yielding a total of 424 subjects. Documentation of the most important indicators of quality as stipulated in national guidelines (i.e., tobacco smoke, spirometry, pharmacological treatment, patient education, and demonstration of inhalation technique) was examined.

Results: Only $22 \%(n=49)$ of the children 6 years of age or older had ever undergone a spirometry test, but the frequency was greater when patients had access to an asthma nurse $(p=0.003)$. Although $58 \%(n=246)$ of the total study population were treated with inhaled steroids, documented patient education and demonstration of inhalation technique was present in 14\% ( $n=59$ ). Exposure to tobacco smoke was documented in $14 \%(n=58)$.

Conclusions: This study reveals a substantial gap between the actual care provided for paediatric asthma and the recommendations formulated in national guidelines.

(C) 2012 Primary Care Respiratory Society UK. All rights reserved.

M Jonsson et al. Prim Care Respir J 2012; 21(3): 276-282

http://dx.doi.org/10.4104/pcrj.2012.00051
\end{abstract}

Keywords asthma care, guidelines, paediatric asthma, primary care

See linked editorial by Bush and Fleming on pg 242

\section{Introduction}

Asthma and other allergic diseases represent the largest group of chronic paediatric diseases in many Western countries. ${ }^{1}$ In Sweden, $8-10 \%$ of children and young people suffer from asthma. ${ }^{2}$ Most children with athma are treated in primary care or paediatric outpatient clinics. The severity of asthma varies greatly and there may

\footnotetext{
* Corresponding author: Mrs Marina Jonsson, Department of Women's and Children's Health, Karolinska Institutet, 17177 Stockholm, Sweden. Tel: 0702831296. E-mail: marina.jonsson@ki.se
} 
be considerable morbidity, especially during periods when symptoms are uncontrolled. ${ }^{3}$ However, with high-quality healthcare providing optimal treatment, most children with asthma can live an active and normal life. ${ }^{4}$ The goal for asthma treatment is that every individual, as far as possible, should live without symptoms and exacerbations. ${ }^{5,6}$ To achieve this goal, children with asthma must get support to manage their disease. . $^{5-10}$

Primary care is the basis of the Swedish healthcare system and is expected to satisfy most patients' needs for medical treatment, care, prevention, and rehabilitation. When more specialised care is required, patients are cared for in hospital-based clinics. Some Primary Healthcare Centres (PHC) have asthma teams including general practitioners (GPs) and a specialised nurse with specific expertise in asthma and allergy, and often also chronic obstructive pulmonary disease (COPD).

The national guidelines for the care and treatment of asthma and COPD are formulated by the National Board of Health and Welfare and include proposed measurable indicators of quality. ${ }^{5.6,8}$ These are available in both paper and web-based formats.

In many cases the control of asthma in children is poor and only a small fraction achieve the desirable level of control set up as a goal by the Global Initiative for Asthma (GINA). ${ }^{910}$ Factors reported to facilitate asthma control include the use of a spirometer and access to a specialised asthma nurse. ${ }^{11,12}$ Having access to an asthma nurse has been shown to increase patients' knowledge, improve asthma care, and reduce costs. ${ }^{13}$

In several fields of medicine, many patients fail to achieve the goals set by evidence-based guidelines ${ }^{14.17}$ and, for adults with asthma, adherence to guidelines in primary care has been reported to be poor. ${ }^{18-20}$ However, the management of asthma and adherence to guidelines for children with this disease by healthcare professionals is unclear. The aim of this study was to evaluate this adherence.

\section{Methods}

\section{Acquiring clinical data}

This cross-sectional survey included 18 PHCs in Stockholm, Sweden and involved two steps. In 2006 the medical records of 81 children aged 6 months to 16 years diagnosed with asthma (ICD code J45) were scrutinised at four PHCs (Figure 1). The four PHCs were selected so that two of them had an asthma nurse specialised in asthma care. Subsequently, in 2007, nurses and general practitioners from $20 \mathrm{PHCS}$ in the northern region of Stockholm were invited to a seminar on paediatric asthma where those attending were asked to participate in the present investigation, of which 14 accepted. In order to obtain patients ranging from 6 months to 16 years in age, the medical records of all children at the total 18 PHCs were divided into four groups on the basis of age. Five children from each group were randomly selected from diagnostics lists.

The medical records of children aged 6 months to 16 years $(n=566)$ diagnosed with asthma ( $n=281)$, obstructive bronchitis (ICD code J22) or cough (ICD code R09) $(n=285)$ at these 14 PHCS between January 2007 to February 2008 were reviewed.
Figure 1. Trial profile: patient selection, inclusion and

\section{final study population}

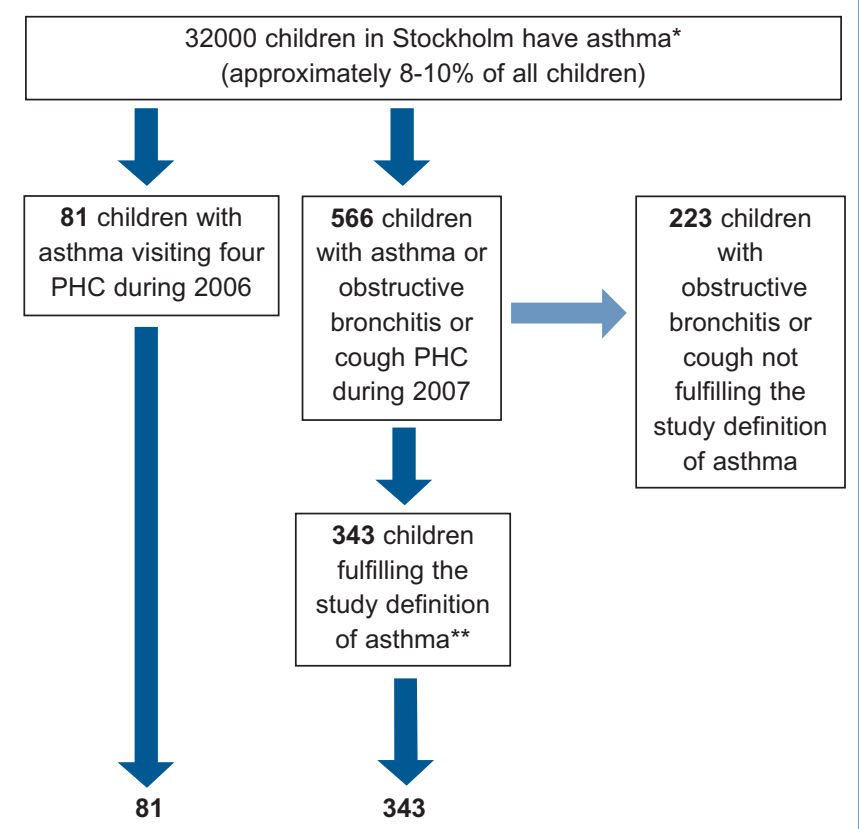

A total of 424 children fulfilling the study definition of asthma**

* Children's health and environment in Stockholm County. Centre for Public Health ISBN: 91-631-9023-0, (2006)

** This study definition of asthma was based either on a diagnosis of asthma documented in the medical record (ISD-10 code J45) or a documented diagnosis of obstructive bronchitis or cough (ISD-10 code J22; R09) the presentation of which fulfilled the evidence based criteria for a diagnosis of asthma as formulated by the National Board of Health and Welfare in Sweden (2004)

\section{Categorisation of data}

All of the medical records ( $n=647$ ) were scrutinised in their entirety (i.e. not only the index visits over 12 months) by two specially trained nurses. De-identified data were marked with a random ID number for each patient and each PHC. The presence of asthma was defined either as a medical diagnosis in the medical record (ISD-10 code J45) or as a recorded diagnosis of obstructive bronchitis (ISD-10 code J22) or cough (ISD-10 code R09) assigned in the medical record, but fulfilling the evidence-based criteria for a diagnosis of asthma as proposed by the Swedish National Board of Health and Welfare in Sweden. ${ }^{6}$ Subsequently, children with a diagnosis of obstructive bronchitis or cough who did not fulfil these latter criteria of asthma $(n=223)$ were excluded, leaving a final study population of 424 children (Figure 1).

A template of predefined indicators of quality of relevance to asthma care was constructed, including information on patient history, clinical examination, as well as pharmacological and nonpharmacological treatment. In addition, the template included information concerning performance of spirometry tests and of pharmacological treatment during the most recent 12-month period (index visits period). 


\begin{tabular}{|c|c|c|}
\hline Indicators of structure & Indicators of process & Indicators of results \\
\hline \multicolumn{3}{|l|}{ Patient history } \\
\hline Allergic co-morbidity & Appropriate documentation & Correct diagnosis \\
\hline Family history of allergic disease & Appropriate documentation & Correct diagnosis \\
\hline Exposure to tobacco smoke & Appropriate documentation & Avoidance of exacerbation (primary and secondary prevention) \\
\hline Furry pets at home & Appropriate documentation & Avoidance of exacerbation (primary and secondary prevention) \\
\hline Indoor environment & Appropriate documentation & Avoidance of exacerbation (primary and secondary prevention) \\
\hline \multicolumn{3}{|l|}{ Clinical examination } \\
\hline Spirometry test at $>6$ yrs of age & Performed & Correct diagnosis and monitoring \\
\hline Peak expiratory flow (PEF) at $>4$ yrs of age & Performed & Correct diagnosis, monitoring and improved self-care \\
\hline Allergy tests & Performed & Avoidance of exacerbation (primary and secondary prevention) \\
\hline \multicolumn{3}{|l|}{ Pharmacological treatment** } \\
\hline Inhaled steroids & Prescribed & Correct treatment, reduced morbidity and improved quality of life \\
\hline Short acting $\beta_{2}$-agonist & Prescribed & Removal of obstruction \\
\hline Acute nebulisation & Performed at the $\mathrm{PHC}$ & Removal of obstruction and reduction of anxiety and morbidity \\
\hline \multicolumn{3}{|l|}{ Non-pharmacological treatment } \\
\hline Patient education & $\begin{array}{l}\text { Documentation of such } \\
\text { education being provided }\end{array}$ & Improved adherence and self-control \\
\hline Planned follow-up & Documentation of such a plan & Improved asthma control \\
\hline
\end{tabular}

Quality was assessed on the basis of indicators of structure, process, and result, in the prioritised areas proposed in the national guidelines for care of childhood asthma ${ }^{6,21}$ shown in Table 1. The structural indicators concern the prerequisites for providing highquality care, process indicators refer to interventions designed to achieve good health, and the result indicators focus on improved functional capacity and health-related quality of life.

The proportions of prioritised actions are presented for the total study population and for the following three subgroups: (1) those provided with access to a specialised asthma nurse; (2) those receiving an initial prescription of inhaled corticosteroids in primary care; and (3) those undergoing regular treatment with inhaled steroids. Information concerning regular treatment with inhaled corticosteroids was only extracted from the medical records from $2007(n=343)$.

The study was approved by the Medical Ethics Committee at Karolinska Institutet.

\section{Statistical analyses}

Statistical values such as proportions and measures of dispersion were computed using standard parametric procedures.

We compared the proportion maintained in medical records within the three subgroups: access to an asthma nurse; initial prescription of inhaled corticosteroids at the $\mathrm{PHC}$; and recommendation of regular treatment with inhaled corticosteroids. The variables in the subgroups were examined from a cluster sample of 18 PHC units. The proportions were calculated and tested in accordance with differences in means for two independent samples adjusted for clustering using the Huber-White sandwich estimator. $^{22,23}$

\section{Results}

All 18 PHCs had a spirometer and a nebuliser for treatment of acute asthma, as well as a pulse oximeter. An asthma nurse and a GP with primary responsibility for asthma care were present at 12 of these centres.

\section{Characteristics of the study population}

Of the 424 children included, 85\% $(n=362)$ had received diagnoses of asthma (ISD-10 code J45) while the remaining 15\% ( $n=62)$ were children with a diagnosis of obstructive bronchitis that fulfilled the criteria for asthma. The study population consisted of slightly more boys (54\%) than girls; $29 \%$ were aged 6 months to 4 years, $23 \%$ were $5-8$ years of age, $23 \%$ were $9-12$ years of age, and $26 \%$ were aged $13-16$ years.

\section{Documentation of areas prioritised in connection with paediatric asthma care according to national guidelines}

\section{Patient history}

The numbers and proportions of children with documented prioritised aspects are presented for the group as a whole and for the three subgroups in Table 2.

Allergic co-morbidity and a family history of allergic disease were documented more frequently than other aspects in the patient history $(67 \%$ ( $n=229)$ vs. $55 \%$ ( $n=230)$ of cases). Data on exposure to tobacco smoke were documented in only $14 \%(n=58)$ and exposure to furry pets at home in $30 \%(n=127)$. The indoor environment was only documented in $5 \%$ of cases $(n=20)$. No statistical differences were observed between the subgroups.

\section{Clinical examination}

In the total study population, 33\% $(n=111)$ had ever performed a 


\begin{tabular}{|c|c|c|c|c|c|c|c|c|c|c|}
\hline \multirow[t]{2}{*}{ Prioritised aspects } & \multirow{2}{*}{$\begin{array}{l}\text { All children } \\
(n=424) \\
\text { Yes }\end{array}$} & \multicolumn{3}{|c|}{$\begin{array}{l}\text { With access to an } \\
\text { asthma nurse }\end{array}$} & \multicolumn{3}{|c|}{$\begin{array}{l}\text { Initial prescription of inhaled } \\
\text { corticosteroids at the PHC }\end{array}$} & \multicolumn{3}{|c|}{$\begin{array}{l}\text { Regular treatment with } \\
\text { inhaled corticosteroids }\end{array}$} \\
\hline & & $\begin{array}{l}\text { Yes } \\
(n=291)\end{array}$ & $\begin{array}{l}\text { No } \\
(n=133)\end{array}$ & $\mathrm{p}$ Value & $\begin{array}{l}\text { Yes } \\
(n=117)\end{array}$ & $\begin{array}{l}\text { No } \\
(n=229)\end{array}$ & $\mathrm{p}$ Value & $\begin{array}{l}\text { Yes } \\
(n=178)\end{array}$ & $\begin{array}{l}\text { No } \\
(n=143)\end{array}$ & $\mathrm{p}$ Value \\
\hline Allergic co-morbidity* & $229(67)$ & $144(63)$ & $85(75)$ & 0.223 & $67(72)$ & $150(66)$ & 0.283 & $120(67)$ & $97(68)$ & 0.954 \\
\hline Family history of allergic disease & $230(55)$ & $142(49)$ & $88(66)$ & 0.188 & $61(52)$ & $157(55)$ & 0.677 & $107(60)$ & $92(64)$ & 0.485 \\
\hline Exposure to furry pets at home & $127(30)$ & $82(28)$ & $45(34)$ & 0.495 & $39(33)$ & $80(28)$ & 0.367 & $65(37)$ & $40(28)$ & 0.116 \\
\hline Exposure to tobacco smoke & $58(14)$ & $44(15)$ & $14(11)$ & 0.445 & $15(13)$ & $41(14)$ & 0.714 & $24(13)$ & $15(11)$ & 0.529 \\
\hline Indoor environment** & $20(5)$ & $14(5)$ & $6(5)$ & 0.922 & $5(4)$ & $14(5)$ & 0.642 & $9(5)$ & $10(7)$ & 0.211 \\
\hline
\end{tabular}

* $(n=343)$; * Information concerning any of the following: ventilation, dampness, mould odour or condensation on the windows.

peak expiratory flow (PEF) test at some time and a third had undergone such a test during the past 12 months (Table 3). Of the children aged 6 years and older, $22 \%(n=49)$ had ever performed a spirometry test and $14 \%(n=37)$ had performed such a test during the past 12 months. A significantly higher proportion of the children cared for at PHCs with an asthma nurse had performed a spirometry test $(p=0.003)$. Those who had been prescribed inhaled steroids $(n=117)$ at a PHC had undergone spirometry tests (18\% vs. $5 \%$; $p=0.032)$ and PEF (37\% vs. $26 \% ; p=0.035)$ more often than those not receiving treatment with inhaled steroids.

\section{Pharmacological treatment}

During the most recent 12-month period, 58\% ( $n=246)$ of the children had been treated with inhaled steroids, $55 \%(n=178)$ of these on a regular basis (Table 4). The GPs at the PHCs involved had initiated and prescribed inhaled corticosteroids in $29 \%$ of the children ( $n=117)$ and, of these, $41 \%(n=49)$ were prescribed regular treatment with inhaled corticosteroids. Treatment with short-acting $\beta_{2}$-agonists had been initiated at the PHC in $41 \% \quad(n=166)$ of children. Montelukast had been prescribed for only a few of the children. Acute treatment by nebuliser had been administered to $22 \%(n=88)$ of the children during the past 12 months, and more frequently $(40 \%)$ in the youngest age group (0-4 years). Half of those receiving such acute treatment were also given oral corticosteroids.

Non-pharmacological treatment

As shown in Table 5, only $14 \%(n=59)$ of the children had ever received patient education regardless of whether or not they had access to an asthma nurse. However, a higher proportion of children treated with inhaled corticosteroids had regularly received patient education compared with those not treated with inhaled corticosteroids ( $22 \%$ vs. $6 \%$; $p=0.006$ ). Documentation was available about smoking cessation in only one case.

Demonstration of the inhalation technique was documented in $14 \%(n=58)$ of the medical records and there was no difference if children had access to an asthma nurse or had been prescribed inhaled steroids at the PHC. Education concerning the use of PEF for

\begin{tabular}{|c|c|c|c|c|c|c|c|c|c|c|}
\hline \multirow[t]{2}{*}{ Prioritised aspects } & \multirow{2}{*}{$\begin{array}{l}\text { All children } \\
(n=424) \\
\text { Yes }\end{array}$} & \multicolumn{3}{|c|}{$\begin{array}{l}\text { With access to an } \\
\text { asthma nurse }\end{array}$} & \multicolumn{3}{|c|}{$\begin{array}{l}\text { Initial prescription of inhaled } \\
\text { corticosteroids at the PHC }\end{array}$} & \multicolumn{3}{|c|}{$\begin{array}{l}\text { Regular treatment with } \\
\text { inhaled corticosteroids }\end{array}$} \\
\hline & & $\begin{array}{l}\text { Yes } \\
(n=291)\end{array}$ & $\begin{array}{l}\text { No } \\
(n=133)\end{array}$ & $p$ Value & $\begin{array}{l}\text { Yes } \\
(n=117)\end{array}$ & $\begin{array}{l}\text { No } \\
(n=286)\end{array}$ & p Value & $\begin{array}{l}\text { Yes } \\
(n=178)\end{array}$ & $\begin{array}{l}\text { No } \\
(n=143)\end{array}$ & p Value \\
\hline Peak expiratory flow $(\mathrm{PEF})^{*}$ test & $117(28)$ & $83(29)$ & $34(29)$ & 0.931 & $43(37)$ & $21(26)$ & 0.035 & $51(29)$ & $39(28)$ & 0.848 \\
\hline $\begin{array}{l}\text { Spirometry test* on children } \\
\text { aged } 6 \text { years or older }\end{array}$ & $37 \quad(14)$ & $35(12)$ & $2(2)$ & 0.003 & $21(18)$ & $16(5)$ & 0.032 & $15(8)$ & $11(8)$ & 0.845 \\
\hline Allergy test** & $124(29)$ & $92(32)$ & $32(24)$ & 0.345 & $41(35)$ & $79(28)$ & 0.166 & $68(38)$ & $32(22)$ & 0.082 \\
\hline
\end{tabular}

Table 4. Numbers $(\%)$ of the medical records for children $(\mathrm{N}=424)$ with asthma that included documentation of prioritised pharmacological treatment

\begin{tabular}{lll} 
Prioritised pharmacological treatment & Yes & No \\
\hline Inhaled steroids: initiated and prescribed at PHC or on regular treatment & $246(58)$ & $178(42)$ \\
\hline Inhaled steroids initiated by PHC & $117(29)$ & $286(71)$ \\
\hline Treatment with inhaled steroid regularly & $178(55)$ & $143(45)$ \\
\hline Short acting $\beta$-agonist initiated by the PHC & $166(41)$ & $237(59)$ \\
\hline Montelukast & $10(2)$ & $392(98)$ \\
\hline
\end{tabular}

PHC=Primary Healthcare Centre. 


\begin{tabular}{|c|c|c|c|c|c|c|c|c|c|c|}
\hline \multirow[t]{2}{*}{$\begin{array}{l}\text { Prioritised non- } \\
\text { pharmacological treatment }\end{array}$} & \multirow{2}{*}{$\begin{array}{l}\text { All children } \\
\text { included } \\
(n=424) \\
\text { Yes }\end{array}$} & \multicolumn{3}{|c|}{$\begin{array}{l}\text { With access to an } \\
\text { asthma nurse }\end{array}$} & \multicolumn{3}{|c|}{$\begin{array}{l}\text { Initial prescription of inhaled } \\
\text { corticosteroids at the PHC }\end{array}$} & \multicolumn{3}{|c|}{$\begin{array}{l}\text { Regular treatment with } \\
\text { inhaled corticosteroids }\end{array}$} \\
\hline & & $\begin{array}{l}\text { Yes } \\
(n=291)\end{array}$ & $\begin{array}{l}\text { Yes } \\
(n=133)\end{array}$ & $\begin{array}{l}\text { No } \\
p \text { Value }\end{array}$ & $\begin{array}{l}\text { Yes } \\
(n=117)\end{array}$ & $\begin{array}{l}\text { No } \\
(n=286)\end{array}$ & $p$ Value & $\begin{array}{l}\text { Yes } \\
(n=178)\end{array}$ & $\begin{array}{l}\text { No } \\
(n=143)\end{array}$ & $p$ Value \\
\hline Patient education* & $59(14)$ & $41(14)$ & $18(14)$ & 0.921 & $23(20)$ & $33(12)$ & 0.110 & $39(22)$ & $9(6)$ & 0.006 \\
\hline Smoking cessation & $1(0.3)$ & $0(0)$ & 1(1) & 0.304 & $0(0)$ & $0(0)$ & $0(0)$ & $0(0)$ & & \\
\hline $\begin{array}{l}\text { Demonstration of inhalation } \\
\text { techniques }\end{array}$ & $58(14)$ & $41(14)$ & $17(13)$ & 0.753 & $23(20)$ & $33(12)$ & 0.107 & $33(19)$ & $1(11)$ & 0.145 \\
\hline $\begin{array}{l}\text { Education of peak expiratory } \\
\text { flow for self-care }\end{array}$ & $30(7)$ & $26(9)$ & $4(3)$ & 0.067 & $13(11)$ & $16(6)$ & 0.048 & $18(10)$ & $7(5)$ & 0.176 \\
\hline A planned follow-up: & $206(51)$ & $15(53)$ & $54(46)$ & 0.423 & $75(64)$ & $129(45)$ & 0.012 & $97(54)$ & $71(50)$ & 0.366 \\
\hline At the PHC & $94(46)$ & $64(25)$ & $30(23)$ & & $40(34)$ & $54(19)$ & & $47(26)$ & $27(19)$ & \\
\hline At the paediatric outpatient clinic & $97(47)$ & $74(49)$ & $23(17)$ & & $31(27)$ & $66(23)$ & & $45(25)$ & $37(26)$ & \\
\hline At another clinic & $15(7)$ & $12(4)$ & $3(2)$ & & $4(3)$ & $11(4)$ & & $5(3)$ & $9(6)$ & \\
\hline
\end{tabular}

self-care at home was documented in $7 \%(n=30)$ of cases, more commonly when the children had been prescribed inhaled steroids (11\% vs. $6 \% ; p=0.048)$.

A follow-up was planned for approximately half of the children with asthma, most commonly at PHCs (46\%) or at paediatric outpatient clinics (47\%). Access to an asthma nurse made no difference in this context. However, children for whom inhaled steroids were prescribed at the PHC were more likely to be followedup (64\% vs. $45 \%$; $p=0.012$ ).

Figure 2 summarises the overall percentage of the medical records that documented fulfilment of none, one, two or three to four of the prioritised actions recommended by all guidelines (i.e. performance of spirometry test, demonstration of the inhalation technique, patient education, and data on exposure to tobacco). None of these prioritised actions were performed in 67\% ( $n=286)$, one was performed in $21 \%(n=87)$, two in $8 \%(n=32)$ and three to four in only $4 \%(n=19)$ of the cases.

\section{Discussion}

\section{Main findings}

The present study - which, to our knowledge, is the first of its kind - shows that the adherence of healthcare professionals in Sweden to guidelines for care of paediatric asthma is poor and that there is considerable room for improvement. Interestingly, the guidelines concerning pharmacological treatment appear to have been implemented more successfully in primary care than those concerning non-pharmacological treatment such as patient education, demonstration of inhalation technique, and information about the importance of smoking cessation. ${ }^{6,24}$

\section{Strengths and limitations of this study}

One strength of the present investigation is that we employed a relatively strict definition of asthma to ensure that the children included actually have asthma and are therefore candidates to undergo the prioritised actions. Furthermore, the medical records were scrutinised in their entirety to make sure no early interventions were missed.

The fact that most of the participating PHCs were represented
Figure 2. Number of actions documented in the medical records showing scores of 0 to 4 of the following prioritised actions in paediatric asthma care: performance of spirometry test, demonstration of inhalation technique, provision of patient education and data on exposure to tobacco smoke

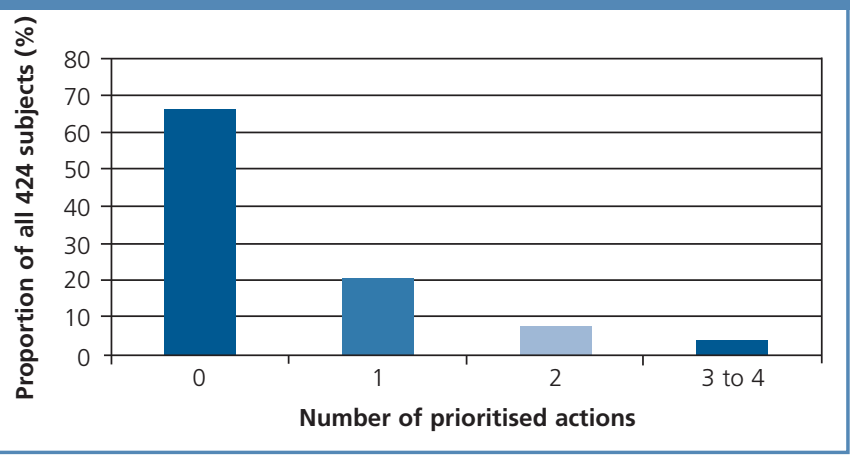

by a nurse and/or GP initially attending a seminar on asthma might have been indicative of a particular interest in paediatric asthma and therefore better adherence to guidelines. However, this situation did not appear to influence the results obtained.

One weakness was our relatively small study population. At the same time, the medical records were selected randomly from PHCs serving a wide range of neighbourhoods and socio-economic groups. In addition, the children were randomly included and stratified by age groups. Furthermore, we had no information of symptom control measured, for example, using the Asthma Control Test $(A C T)$. However, in routine primary care the ACT test is not commonly used.

We are aware that not all information and actions are accurately documented in medical records, even though the guidelines and Swedish law ${ }^{25}$ clearly state that all healthcare professionals must provide such documentation to ensure high-quality and safe care. Interpretation of findings in relation to previously published work

Adhering to guidelines in routine daily practice is a task of great 
complexity. Guidelines are often thoroughly written regarding what to do according to the evidence. However, they seldom include guidance on how to alter practice in the context of everyday primary care.

Available guidelines ${ }^{26}$ indicate that $80 \%$ of all children with asthma should require treatment with inhaled steroids or leukotriene antagonists, a proportion greater than the $58 \%$ treated in this study. It is also essential to ensure the lowest possible doses are used to achieve symptom control to minimise the risk of adverse effects. ${ }^{27}$ Of the $58 \%$ of children in this study treated with inhaled steroids, only $14 \%$ had been given a demonstration of the inhalation technique.

Only $14 \%$ of the children had received patient education, which is considered to have an important role in asthma care. ${ }^{6}$ Several studies have demonstrated the importance of patient education and routine follow-up. ${ }^{28,29}$ Moreover, although it is generally recognised that treatment should be based on an agreement between the patient and caregivers, ${ }^{30-32}$ asthma care often fails to incorporate the view of the patient. ${ }^{33}$

Furthermore, although the importance of using a proper inhalation technique is highlighted in all guidelines, ${ }^{5,6}$ most of the children in our investigation had never received instructions in the technique. This is in line with a report from the USA where, in most cases, metered-dose inhalers were neither demonstrated nor assessed in connection with paediatric asthma visits. ${ }^{34}$ Clearly, it is important to ascertain proper use of the inhalation technique at each clinic and with each visit. ${ }^{35}$

Information concerning exposure to tobacco smoke was present in $14 \%$ of the medical records and advice to stop smoking was documented in only one case, even though this action has one of the highest priorities in healthcare. ${ }^{5,6}$ Exposure to tobacco is one of the major causes of deterioration in children with asthma. ${ }^{36,37}$ Children with asthma have a higher risk of hospitalisation if their parents smoke than asthmatic children with non-smoking parents. ${ }^{38,39}$ In addition, a Swedish study recently showed that direct or indirect exposure to tobacco is positively correlated with the incidence of asthma and wheeze in teenagers. ${ }^{40}$ Healthcare providers who care for children with asthma need to be better at raising awareness of the effects of smoking and the importance of reducing childhood exposure to tobacco. ${ }^{5,6}$

The spirometry test is an important tool in both the diagnosis and monitoring of paediatric asthma and has a high priority in national and international guidelines; ${ }^{5,6}$ furthermore, its use improves asthma control. ${ }^{41} \mathrm{~A}$ study in primary care from Canada showed the importance of using a spirometer as part of the control index for patients from 6 years of age..$^{42}$ In the present study, only a minority of the children older than 6 years of age had ever undergone a spirometry test even though all the PHCs had access to a spirometer.

In the present investigation, access to an asthma nurse was not associated with any substantial improvement in the performance of prioritised actions except that a higher proportion of children with such access had performed a spirometry test. These findings are not consistent with other reports showing that access to an asthma nurse in primary care improves knowledge about and control of the disease, as well as quality of life. ${ }^{11,13}$ In addition, a Dutch study showed that care provided by a specialised asthma nurse is as effective in the outpatient management of stable childhood asthma as traditional management by a paediatrician or GP. ${ }^{43}$ Furthermore, attention to clinical guidelines can improve evidence-based nursing practice in connection with the non-pharmacological management necessary for optimal treatment of childhood asthma in which specialised asthma nurses are highly skilled. ${ }^{44}$

Despite the obvious importance of a planned follow-up visit for asthma control as emphasised in national guidelines, only half of the children had a planned follow-up. Such a follow-up should include an assessment of asthma control, comprehensive patient education, demonstration of the inhalation technique, implementation of a self-management plan, and a routine medical examination. 5,6,45

Of the children who had received a diagnosis of obstructive bronchitis or cough at the studied PHC, 22\% fulfilled the evidencebased criteria of asthma provided by national or international guidelines. Obviously, if the diagnosis is incorrect, treatment may be inappropriate which could result in more unplanned visits due to obstructive symptoms as well as a lower quality of life. On the other hand, diagnosing asthma in children aged 5 years or younger is not easy since respiratory symptoms such as wheeze and cough are generally common in this age group..$^{46,47}$

\section{Implications for future research, policy and practice}

Further studies are needed to understand the complex connection between what to do according to guidelines and how to organise healthcare so that, in practice, support is provided in accordance with guidelines. Adherence to guidelines for primary care of paediatric asthma appears to be poor and should be improved. This situation must be considered when planning education strategies and organising the care of children with asthma.

\section{Conclusions}

This review of medical records reveals a clear gap between the actual care provided to children with asthma and national guidelines. For a large proportion of these children, many of the prioritised actions were not performed which might have increased morbidity. Clinical examination and non-pharmacological treatment were the lowest with respect to adherence to guidelines, both with and without access to an asthma nurse.

\section{Handling editor David Bellamy Statistical review Gopal Netuveli}

Acknowledgements The authors are grateful to Ann Berglind, nurse at Astrid Lindgrens Hospital, Karolinska University Hospital, and Gun-Britt Eriksdotter, nurse at Centre for Allergy Research, Karolinska Institutet, for scrutinising the medical records. They also thank statistician Tomas Lind and data manager Andre Lauber, Institute of Environmental Medicine, Karolinska Institutet, and Joe de Pierre, Unit of Biochemical Toxicology, Stockholm University for revision of the English text. Conflicts of interest The authors declare that they have no conflicts of interest in relation to this article.

Contributorship The authors' contributions were as follows: MJ, IKR(Ingvar Krakau), GH, IK (Inger Kull), MI, AK, ACE planned the present study. IK, AK and ACE supervised the data collection and $\mathrm{MJ}$ collected the data. MJ, MI and EH prepared the data for analysis. MJ performed the analysis. MJ, IK, IKR, AK, ACE, MI, EH, GH intepreted the data. MJ drafted the manuscript and MJ, IK, AK, ACE, GH, IKR, MI and $\mathrm{EH}$ provided critical review of the manuscript.

Funding This study was supported by financial grants from the Centre for Allergy Research, Karolinska Institutet, Asthma and Allergy Foundation and the Samariten Foundation. 


\section{References}

1. Statistics Sweden (SCB). Available from: http://www.scb.se.

2. Centre for Public Health. Children's health and environment in Stockholm County. 2006.

3. O'Connell EJ. The burden of atopy and asthma in children. Allergy 2004;59(Suppl 78):7-11. http://dx.doi.org/10.1111/j.1398-9995.2004.00563.x

4. Bateman ED, Boushey HA, Bousquet J, et al. Can guideline-defined asthma control be achieved? The Gaining Optimal Asthma ControL study. Am J Respir Crit Care Med 2004;170(8):836-44. http://dx.doi.org/10.1164/rccm.200401-0330C

5. Global Initiative for Asthma (GINA). The global strategy for asthma management and prevention, 2007. Available from: http://www.ginasthma.org

6. National Board of Health and Welfare, Sweden. Guidelines for asthma and chronic obstructive lung disease. Stockholm, 2004.

7. Hälso och sjukvården i Sverige, Faktablad, Socialdepartementet (Health Care in Sweden, facts documents from the Ministry of Health and Social Affaires in Sweden). No 14 June, 2007. Available from http://www.regeringen.se/sb/d/14832

8. Swedish Council on Technology Assessment in Health Care (SBU). Treatment of asthma and COPD. Stockholm, 2000.

9. Gustafsson PM, Watson L, Davis KJ, Rabe KF. Poor asthma control in children: evidence from epidemiological surveys and implications for clinical practice. Int J Clin Pract 2006;60(3):321-34. http://dx.doi.org/10.1111/j.1368-5031.2006.00798.x

10. Rabe KF, Adachi M, Lai CK, et al. Worldwide severity and control of asthma in children and adults: the global asthma insights and reality surveys. J Allergy Clin Immuno/ 2004;114(1):40-7. http://dx.doi.org/10.1016/j.jaci.2004.04.042

11. Lisspers K, Stallberg B, Hasselgren M, Johansson G, Svardsudd K. Primary health care centres with asthma clinics: effects on patients knowledge and asthma control. Prim Care Respir J 2010;19(1):37-44. http://dx.doi.org/10.4104/pcrj.2009.00043

12. Tzeng LF, Chiang LC, Hsueh KC, Ma WF, Fu LS. A preliminary study to evaluate a patient-centred asthma education programme on parental control of home environment and asthma signs and symptoms in children with moderate-to-severe asthma. J Clin Nurs 2010;19(9-10):1424-33. http://dx.doi.org/10.1111/j.1365-2702.2009.03021.x

13. Lindberg $M$, Ahlner J, Ekstrom $T$, Jonsson $D$, Moller $M$. Asthma nurse practice improves outcomes and reduces costs in primary health care. Scand J Caring Sci 2002;16(1):73-8. http://dx.doi.org/10.1046/j.1471-6712.2002.00054.x

14. Carlfjord S, Lindberg M. Asthma and COPD in primary health care, quality according to national guidelines: a cross-sectional and a retrospective study. BMC Fam Pract 2008;9:36. http://dx.doi.org/10.1186/1471-2296-9-36

15. Stallberg B, Lisspers K, Hasselgren M, Janson C, Johansson G, Svardsudd K. Asthma control in primary care in Sweden: a comparison between 2001 and 2005. Prim Care Respir J 2009;18(4):279-86. http://dx.doi.org/10.4104/pcrj.2009.00024

16. Mclvor RA, Boulet LP, FitzGerald JM, Zimmerman S, Chapman KR. Asthma control in Canada: no improvement since we last looked in 1999. Can Fam Physician 2007;53(4):673-7, 2.

17. Kotseva K, Wood D, De Backer G, De Bacquer D, Pyorala K, Keil U. Cardiovascular prevention guidelines in daily practice: a comparison of EUROASPIRE I, II, and III surveys in eight European countries. Lancet 2009;373(9667):929-40. http://dx.doi.org/10.1016/S0140-6736(09)60330-5

18. Boulet LP. Improving knowledge transfer on chronic respiratory diseases: a Canadian perspective. How to translate recent advances in respiratory diseases into day-to-day care. J Nutr Health Aging 2008;12(10):758S-63S.

19. Wiener-Ogilvie S, Pinnock H, Huby G, Sheikh A, Partridge MR, Gillies J. Do practices comply with key recommendations of the British Asthma Guideline? If not, why not? Prim Care Respir J 2007;16(6):369-77. http://dx.doi.org/10.3132/pcrj.2007.00074

20. Lisspers K, Stallberg B, Hasselgren M, Johansson G, Svardsudd K. Organisation of asthma care in primary health care in mid-Sweden. Prim Care Respir J 2005;14(3):147-53. http://dx.doi.org/10.1016/j.pcrj.2005.03.003

21. Mainz J. Defining and classifying clinical indicators for quality improvement. Int $J$ Qual Health Care 2003;15(6):523-30. http://dx.doi.org/10.1093/intqhc/mzg081

22. Huber PJ. The behavior of maximum likelihood estimates under nonstandard conditions. Proceedings of the Fifth Berkeley Symposium on Mathematical Statistics and Probability. Berkeley: University of California Press, 1967. Volume 1. p.221-33.

23. Rogers $W H$. Regression standard errors in clustered samples. Stata Technical Bulletin Reprints 13: 19-23. Reprinted in Stata Technical Bulletin Reprints, Volume 3, p.88-94. College Station, TX: Stata Press, 1993

24. Chang C. Asthma in children and adolescents: a comprehensive approach to diagnosis and management. Clin Rev Allergy Immunol 2011 Mar 29. http://dx.doi.org/10.1007/s12016-011-8261-3
25. National Board of Health and Welfare in Sweden. Socialstyrelsen föreskrifter om informationshantering och journalföring i hälso och sjukvården (Prescriptions of information management and recordkeeping in health care). Available from www.socialstyrelsen.se/sosfs/2008-14.

26. Medical Products Agency Sweden. Asthma pharmacological treatment. 2007.

27. Randell TL, Donaghue KC, Ambler GR, Cowell CT, Fitzgerald DA, van Asperen PP. Safety of the newer inhaled corticosteroids in childhood asthma. Paediatr Drugs 2003;5(7):481-504.

28. Gibson PG, Powell H, Coughlan J, et al. Self-management education and regular practitioner review for adults with asthma. Cochrane Database Syst Rev 2003;(1):CD001117.

29. Espinoza-Palma T, Zamorano A, Arancibia F, et al. Effectiveness of asthma education with and without a self-management plan in hospitalized children. J Asthma 2009;46(9):906-10. http://dx.doi.org/10.3109/02770900903199979

30. Gillisen A. Patient's adherence in asthma. J Physiol Pharmacol 2007;58(Suppl 5(Pt 1):205-22.

31. Bodenheimer T, Lorig K, Holman H, Grumbach K. Patient self-management of chronic disease in primary care. JAMA 2002;288(19):2469-75. http://dx.doi.org/10.1001/jama.288.19.2469

32. Sarver N, Murphy K. Management of asthma: new approaches to establishing control. J Am Acad Nurse Pract 2009;21(1):54-65. http://dx.doi.org/10.1111/j.1745-7599.2008.00375.x

33. Ring $N$, Jepson $R$, Hoskins $G$, et al. Understanding what helps or hinders asthma action plan use: a systematic review and synthesis of the qualitative literature. Patient Educ Couns 2011;85(2):e131-43. http://dx.doi.org/10.1016/j.pec.2011.01.025

34. Sleath B, Ayala GX, Gillette $C$, et al. Provider demonstration and assessment of child device technique during pediatric asthma visits. Pediatrics 2011;127(4):642-8. http://dx.doi.org/10.1542/peds.2010-1206

35. Munzenberger PJ, Thomas R, Bahrainwala A. Retention by children of device technique for inhaled asthma drugs between visits. J Asthma 2007;44(9):769-73. http://dx.doi.org/10.1080/02770900701645793

36. Carlsen KH, Carlsen KC. Respiratory effects of tobacco smoking on infants and young children. Paediatr Respir Rev 2008;9(1):11-20. http://dx.doi.org/10.1016/j.prrv.2007.11.007

37. Carlsen KH, Lodrup Carlsen KC. Parental smoking and childhood asthma: clinical implications. Treat Respir Med 2005;4(5):337-46. http://dx.doi.org/10.2165/00151829-200504050-00005

38. Cinar N, Dede C, Cevahir R, Sevimli D. Smoking status in parents of children hospitalized with a diagnosis of respiratory system disorders. Bosn J Basic Med SCi 2010;10(4):319-22.

39. Gerald LB, Gerald JK, Gibson L, Patel K, Zhang S, McClure LA. Changes in environmental tobacco smoke exposure and asthma morbidity among urban school children. Chest 2009;135(4):911-16. http://dx.doi.org/10.1378/chest.08-1869

40. Hedman L, Bjerg A, Sundberg S, Forsberg B, Ronmark E. Both environmental tobacco smoke and personal smoking are related to asthma and wheeze in teenagers. Thorax 2011;66(1):20-5. http://dx.doi.org/10.1136/thx.2010.143800

41. Stout JW, Visness CM, Enright $P$, et al. Classification of asthma severity in children: the contribution of pulmonary function testing. Arch Pediatr Adolesc Med 2006;160(8):844-50. http://dx.doi.org/10.1001/archpedi.160.8.844

42. Dostaler SM, Olajos-Clow JG, Sands TW, Licskai CJ, Minard JP, Lougheed MD. Comparison of asthma control criteria: importance of spirometry. I Asthma 2011;48(10):1069-75. http://dx.doi.org/10.3109/02770903.2011.631243

43. Kuethe $M$, Vaessen-Verberne A, Mulder P, Bindels $P$, van Aalderen W. Paediatric asthma outpatient care by asthma nurse, paediatrician or general practitioner: randomised controlled trial with two-year follow-up. Prim Care Respir J 2011;20(1):84-91. http://dx.doi.org/10.4104/pcrj.2011.00003

44. Alanen S, Valimaki M, Kaila M. Nurses' experiences of guideline implementation: a focus group study. J Clin Nurs 2009;18(18):2613-21. http://dx.doi.org/10.1111/j.1365-2702.2008.02754.x

45. Guarnaccia S, Lombardi A, Gaffurini A, et al. Application and implementation of the GINA asthma guidelines by specialist and primary care physicians: a longitudinal follow-up study on 264 children. Prim Care Respir J 2007;16(6):357-62. http://dx.doi.org/10.3132/pcrj.2007.00077

46. Doherty G, Bush A. Diagnosing respiratory problems in young children. Practitioner 2007;251(1697):20,22-5.

47. Pedersen S. Preschool asthma - not so easy to diagnose. Prim Care Respir $J$ 2007;16(1):4-6. http://dx.doi.org/10.3132/pcrj.2007.00011 